\title{
Development of the Specific Gravitational Model Describing Foreign Trade Between Two Countries with Simulation Method
}

\author{
Giorgi Gaganidze \\ Faculty of Economics and Business \\ Tbilisi State University \\ Tbilisi, Georgia \\ e-mail: giorgi.gaganidze@tsu.ge
}

\author{
Tea Munjishvili \\ Faculty of Economics and Business \\ Tbilisi State University \\ Tbilisi, Georgia \\ e-mail: tea.munjishvili@tsu.ge \\ https://orcid.org/0000-0001-8578-4470
}

\begin{abstract}
The Course of joining the European Union was declared by three other States (Georgia, Moldova, Ukraine) only in 2014 when they signed the Association Agreement. These Agreements turned out to be quite challenging for the States as they impose huge obligations: in the field of Foreign Trade among others. These are the topics of major interest for the present article, in which we use the techniques of comparative analysis. The Analysis is focused on several aspects of foreign trade, such as export geography, major exporting products, changes in foreign trade, based on the assumption that Association Agreement would positively influence export potential and scales of export on the EU market Analyze and dynamic formation of the change impact of export/import with the specific countries, on GDP of Georgia, is carried out by the computer programs, after development of specific gravitational model.
\end{abstract}

Gravitational model describing Georgia's Foreign Trade Relations is developed by the simulation method. Determination of optimal values of coefficients existing within the models is carried out by our developed computer program, not by the linear optimization method within the scope of simulation mode.

Keywords - Gravitational model, Simulation method, Optimization task, Foreign Trade.

\section{INTRODUCTION}

The article examines the foreign trade of Georgia, have the same historical background, clearly indicate the European development path and pursue the same goal - they strive to become members of Euro-Atlantic structures, as evidenced by the signing of an association agreement with the European Union. The association agreement with the EU created a new reality, where the existing export products are oriented on the EU market, rather than CIS; at the same time there are some possibilities to create new exporting products mainly by attracting Foreign Direct Investments (FDI).

We should also analyze the NAFTA direction. It should be mentioned that for Georgia North America has always been an important export market, which is why the Georgian Government is seeking to launch a free trade agreement with the USA. In addition, we should note that even with FTA,
Georgia will be able to re-allocate existing exporting products, while for new export products the country will need solid FDI growth.

The Gravitational models have been widely used within the research of the foreign trade processes. Foreign trade scope's functional dependence with some macroeconomic indicators-GDP, capacity of internal market and others [1] is discussed within the model. It's approved that the scope of the foreign trade is proportional to macroeconomic indicators, including GDP and inversely proportionate to the distance between the countries.

\section{RESULTS OF STUDIES}

Our research and to clarify how the export potential is utilized, we'll use Trade Intensification Index. The Index will be computed for the major export destinations (EU, CIS, and NAFTA). The index gives us good opportunity to assess the utilization of the export potential country or country group. The formula of the index is: $X_{i j}-i$ country export in $j$ country; $X_{i}-i$ country total export; $M_{j}-j$ country total imports; $M-$ world import. Formula is: $I_{i j}=\left(X_{i j} / X_{i}\right) /\left(M_{j} / M\right)$. If the figure Iij is higher than 1 , then your trading partner is more important to you, than you are to the trading partner. If the figure equals 1 , it means, that your export utilization is proportional, if the figure is less than 1 , your export potential is underutilized. Underutilization could be computed as the difference between export figures when index equals 1 , and the actual exports.

TABLE I. TRADE INTENSIFICATION INDEX

\begin{tabular}{|c|c|c|c|}
\hline Country & EU & CIS & NAFTA \\
\hline Georgia & 0.84 & 13.5 & 0.32 \\
\hline
\end{tabular}

The gravitational model of the Jan Tinbergen, Nobel Prize laureate in the Economy is the base of gravitational models developed within some countries, considering some peculiarities of the specific countries. Modification of the mentioned model is carried out quite often; in particular-some parameters are added, such as: existence of common land border with the respondent country, as well as access to the sea of the respondent country [2]. Indicators such as _custom 
tariffs, transport expenses, membership of trade unions, currency rate, political ties, military blocks, language barriers, etc., used within the gravitational models are systemized. In Most cases we are dealing with varieties of this model.

\section{A. Methods}

We have used simulation method for development of specific gravitational model describing foreign trade relations between two countries. Establishment of optimal values of coefficients included within the model -GDP, distance between the countries, trading preferences and other considerations- specific data of Georgia and other respondent countries, is carried out within the simulation mode.

If the figure $I_{i j}$ is greater than 1 , then your trading partner is more important to you, than you are to the trading partner. If the figure equals 1 , it means, that your export utilization is proportional, if the figure is less than 1 , your export potential is underutilized.

Our First aim is to work out specific gravitational model describing foreign trade between two countries, by simulation method;

Second aim is to study the impact of the change of volume of export/import on GDP of Georgia, using the worked out model.

The Object of the research is our developed Gravitational model of the foreign trade of Georgia, worked out on the base of the models belonging to $Y$. Izard and J. Tinbergen [3], Models SAQ1 and SAQ2 have a logarithmic form:

SAQ1 model:

$Q_{i, j}=\ln b_{1}+b_{2} * \ln X 1-b_{3} * \ln X 2+b_{4} * X 3+b_{5} * X 4+b_{6} *$ $X 5+b_{7} * X 6+b_{8} * X 7$

SAQ2 model:

$Q_{i, j}=\ln b_{1}+b_{2} * \ln X 1-b_{3} * \ln X 3+b_{4} * \ln X 2+b_{5} * X 4+b_{6} *$ $X 5+b_{7} * X 6+b_{8} * X 7$

Symbols used in SAQ1 and SAQ2 models have the following content significance:

$Q_{i, j}$ : Volume of Export from $i$ country (Georgia) to $j$ country or Import from $j$ country, within $t$ time period.

$D_{i, j}$ : Distance between $i$ country (Georgia) and $j$ respondent country, in kilometers.

$X 1_{i}$ : GDP of $i$ country (Georgia) within $t$ time period.

$X 2_{j}$ : GDP of $j$ respondent country within $t$ time period.

$X 3_{i, j}$ : Having common land border between $i$ country (Georgia) and $j$ respondent country.

$X 4_{i, j}$ : Possibility of $i$ country (Georgia) of having connection to respondent $j$ country through the sea.

$X 5_{i, j}$ : Trade preferences between $i$ country (Georgia) and $j$ respondent country.

$X 6_{i, j}$ : Historical-cultural relation between $i$ country (Georgia) and $j$ respondent country.

$X 7_{i, j}$ : Politicial relation between $i$ country (Georgia) and $j$ respondent country.
SAQ3 model has a form:

$$
\begin{aligned}
S A Q 3=\ln (0.7769848)+0.9082364 * \ln (X 1) \\
+0.163151 * \ln (X 2)-1.018411 * \ln (X 3) \\
+0.1106653 * X 4+0.1109382 * X 5 \\
+0.9929988 * X 6+0.02021067 * X 7 \\
+0.2547248 * X 8
\end{aligned}
$$

where:

X1: GDP of Georgia;

X2: GDP of the respondent;

X3: Distance between Georgia and the respondent country;

X4: Common land border;

X5: Access to the see of the respondent;

X6:Trade preferences;

X7: Cultural relation;

X8: Political relation;

SAQ4 of Foreign Trade import exchange model is as follows:

$\mathrm{Q}=\mathrm{Ln}(\mathrm{b} 1)+\mathrm{X} 5 * \mathrm{Ln}(\mathrm{X} 3)-\mathrm{X} 5 * \mathrm{Ln}(\mathrm{X} 4)+\mathrm{X} 7 * \mathrm{Ln}$ $((1+\mathrm{X} 6)+\mathrm{Ln}(\mathrm{X} 2) *(1+\mathrm{X} 8)+\mathrm{b} 2 * \mathrm{X} 9+\mathrm{b} 3 * \mathrm{X} 10+\mathrm{b} 4$ $* \mathrm{X} 1+\mathrm{b} 5$

where:

$\mathrm{X} 1$ - $i$ - goods internal market capacity;

X2 - import price $i$ - goods;

X3 - domestic use Price $i$ - goods;

X4 - import levy;

X5 - elasticity coefficient;

X6 -import.

Distance between the capitals of the countries is considered as the distance between the countries. Values of $\mathrm{X} 1, \mathrm{X} 2$ are taken from $[4,5]$. Values $\mathrm{X} 3, \mathrm{X} 4, \mathrm{X} 5$ get two values 1 - from the boundary, the presence of preferences, 0 - opposite cases. X6, X7 takes values: 1 - good; 0,5 medium; 0 - bad.

Foreign trade is one component of the analysis of foreign trade activities of indexes, such as: intensity, normalization, concentration - Hirshman, Grubel-Lloyd, concentration Gaganidze index [6]. Gaganidze index is drawing. It is calculated by the formula:

$$
\mathrm{Q} \_g=\left(E \_i \wedge t\right) /\left(I \_s^{\wedge} t\right)
$$

where:

$\mathrm{E} \_\mathrm{i} \wedge \mathrm{t}-$ exports of goods of respondents in the country;

$\mathrm{I} \_\mathrm{s} \wedge \mathrm{t}$ - the goods imported from all countries of the respondents;

$\mathrm{E} \_\mathrm{s} \wedge \mathrm{t}$ - the respondent country's total exports in all countries; 
SAQ _ $\mathrm{s}^{\wedge} \mathrm{t}$ - total exports of all countries.

Finding the values of optimal coefficients of $b_{j}, j=$ $\overrightarrow{1 . . m}$ within the simulation mode is carried out by solving of optimization task.

Is given:

The minimum and maximum values of the coefficients $b_{k}, k=\overrightarrow{1 . . m}$ is defined within simulation mode of $\min _{k}=0.0001 . \quad \max b_{k}$, forensically. Such values of $b_{k}$ is chosen at which time the calculated maximum values of $Q_{i, j}$ is few times more than the factual value of $Q_{i, j}$.

$X_{i} \quad i=\overrightarrow{1 . . n}$ Values of variables $-X_{i} \geq 0$.

Necessary to:

Find the values $\min _{k} \leq b_{k} \leq \max b_{k}$ of $b_{k}, k=$ $\overrightarrow{1 . . m}$ coefficients at which time $Q_{i, j}^{t, \text { fact. }}-Q_{i, j}^{t, \text { count }} \leq \sigma$ is calculation inaccuracy and is less than $3 \%$.

Considering the model, the hereof task belongs to not linear optimization task. Option of $Q_{i, j}$, satisfying condition of the task shall be chosen within the simulation mode. Searched $Q_{i, j}$ relevant $b_{k}, k=\overrightarrow{1 . . m}$ values are considered as basic option.

Development of the specific gravitational models and formation numbers of decisions on the base of the mentioned model is implemented by our worked out computer program, by simulator SAGAREO 1.0.

Finding out optimal value $b_{k}, k=\overrightarrow{1 . . m}$ and accordingly solving nonlinear optimization task is carried out by the Solver program, existing within the Excel. Choosing of optimal option is done through evolutionary method existing within the Solver.

Establishment of the Value of GDP through the change of Export or Import $X 1=f\left(Q_{i, j}\right)$ is carried out by the program - Goal Seek, existing within Excel. Visualization of the modeling results is carried out by graphs and reports.

TABLE II. ESTABLISHMENT THE VALUE OF GDP THROUGH THE CHANGE OF EXPORT

\begin{tabular}{|c|c|c|c|c|c|}
\hline 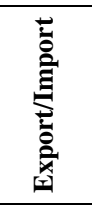 & $\frac{\bar{d}}{\stackrel{D}{c}}$ & $\stackrel{\vec{E}}{\Xi}$ & 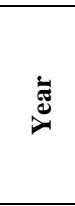 & 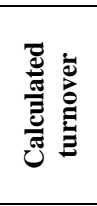 & 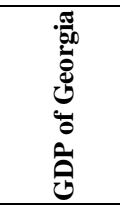 \\
\hline Export & SAQ3 & Turkey & 2017 & 216674 & 15160352 \\
\hline Export & SAQ3 & Turkey & 2017 & 266674 & 19055516 \\
\hline Export & SAQ3 & Turkey & 2017 & 316674 & 23034846 \\
\hline Export & SAQ3 & Turkey & 2017 & 366674 & 27074683 \\
\hline Export & SAQ3 & Turkey & 2017 & 416674 & 31168861 \\
\hline Export & SAQ3 & Turkey & 2017 & 466674 & 35312108 \\
\hline Export & SAQ3 & Turkey & 2017 & 516674 & 39485031 \\
\hline Export & SAQ3 & Turkey & 2017 & 566674 & 43720154 \\
\hline
\end{tabular}

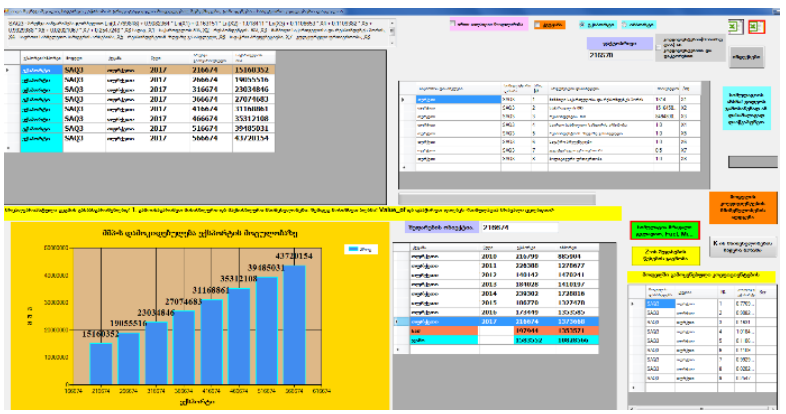

FIG. 1. RESULTS OF MODELING BASED ON THE SPECIFIC GRAVITATIONAL MODEL $\boldsymbol{X} \mathbf{1}=\boldsymbol{f}\left(\boldsymbol{Q}_{i, j}\right)$ OF THE FOREIGN TRADE BETWEEN TWO COUNTRIES

\section{CONCLUSION}

1. It is justified to select from the multiplicity of foreign trade models in the simulation mode and to develop a specific model for the given country that will be represented by the coefficients from the standard model;

2. Foreign trade-economic models using mathematical models needed for the general to be selected or developed for the first - and second general gravitational model - statistical data processing of the simulation mode is developed between the two countries, foreign trade analysis, specific gravity model.

3. The gravitational model of foreign trade of Georgia is developed by simulation method. Determination of the optimal values of the coefficients in the model is performed by a non -linear optimization method in computer simulation developed by us;

4. Following the development of a specific gravitational model, a computer program shall formulate and analyze the dynamics of the impact of export / import change on a specific country of GDP in Georgia.

5. From the mathematical model used in economics, it is selected and substantiated, after many variants of the gravitational model of foreign trade are adopted, to choose the optimal one based on our logical probability model;

6. The use of any simulator, including SAGARE2019, is not a panacea. It is one of the ways to delve deeper into the issue. Here the effect of using a simulator is achieved by using a properly designed electronic manual with the use of a computer simulator;

7. An integral part of the simulation is debriefing and analysis of results. With SAGARE2019, the teacher will receive a training and simulation protocol for group debriefing.

8. SAGARE2019 can be used: When training specialists in different countries with a single legal space and to train specialists for the settlement of foreign trade.

\section{REFERENCES}

[1] P. R. Krugman, International economics: theory \& policy, P. R. Krugman, M. Obstfeld, M. J. Melitz. - 9th ed. -Boston: Pearson Education, Inc, 2012.

[2] J.E. Anderson, and E. van Wincoop, "Trade Costs", Journal of Economic Literature, 42, pp. 691-751, 2004

[3] J. Tinbergen, The Use of Models: Experience and Prospects . [Online] Available: https://www.nobelprize.org/prizes/economic-sciences/ 1969/tinbergen/lecture/. Accessed on: May 29, 2019. 
[4] National Statistica office of Georgia. [Online]. Available: https://www.geostat.ge/en. Accessed on: May 29, 2019.

[5] World

Data

Atlas.

[Online].

Available: https://knoema.com/atlas?origin=knoema.ru. Accessed on: May 29, 2019.

[6] G. Gaganidze, "Georgian Export Potential Utilization on the EU Market”, Journal of International Management Studies, vol. 16, no. 1, pp.13-18, 2016
[7] T. Munjishvili, "Developing enterprise financial sustainability and bankruptcy Forecasting model in specific economic-mathematical environment using simulation method, Information Theories and Applications, vol. 26, no. 3, pp. 285-299, 2019

[8] Sakarya, S., Eckman, M., and Hyllegard, K. H. "Market selection for international expansion: Assessing opportunities in emerging markets “, International Marketing Review, Vol. 24(2), pp. 208-238, 2007. 